\title{
Selective reversal of muscle relaxation in general anesthesia: focus on sugammadex
}

This article was published in the following Dove Press journal:

Drug Design, Development and Therapy

22 April 2009

Number of times this article has been viewed

\author{
Sorin J Brull' \\ Mohamed Naguib ${ }^{2}$ \\ ' Department of Anesthesiology, Mayo \\ Clinic College of Medicine, Mayo \\ Clinic Hospital, Jacksonville, FL, USA; \\ ${ }^{2}$ Department of Anesthesiology \\ and Pain Medicine, The University \\ of Texas M D Anderson Cancer \\ Center, Houston, TX, USA
}

\begin{abstract}
Despite the significant improvements in the pharmacology of muscle relaxants in the past six decades, the search for the ideal muscle relaxant continues, mainly because of the incomplete efficacy and persistent side effects associated with their antagonism. Clinical concerns remain about the residual paralysis and hemodynamic side effects associated with the classic pharmacologic reversal agents, the acetylcholinesterase inhibitors. Although the development of the "ideal muscle relaxant" remains illusory, pharmacologic advancements hold promise for improved clinical care and patient safety. Recent clinical advances include the development of short-acting nondepolarizing muscle relaxant agents that have fast onset and a very rapid metabolism that allows reliable and complete recovery; and the development of selective, "designer" reversal agents that are specific for a single drug or class of drugs. This article reviews recent developments in the pharmacology of these selective reversal agents: plasma cholinesterases, cysteine, and sugammadex. Although each of the selective reversal agents is specific in its substrate, the clinical use of the combination of muscle relaxant with its specific reversal agent will allow much greater intraoperative titrating ability, decreased side effect profile, and may result in a decreased incidence of postoperative residual paralysis and improved patient safety.
\end{abstract}

Keywords: selective reversal agents, cysteine, plasma cholinesterases, sugammadex

Arguably, one of the most significant developments in surgery over the past century has been the introduction of muscle relaxation provided by the administration of neuromuscular blocking drugs. While initially the use of curare was reported to be associated with significant perioperative morbidity and mortality, ${ }^{1}$ at the same time, the provision of markedly improved surgical conditions (flaccid paralysis) afforded by muscle relaxants has allowed significant advances in surgery.

The first administration of anesthesia via a tracheostomy by Friedrich Trendelenburg in $1871^{2}$ was followed soon by the first report of endotracheal intubation for anesthesia by William MacEwen in 1880 to prevent aspiration of blood during oral surgery. ${ }^{3}$ Although orotracheal intubation did not become routine in clinical medicine until the 1940s, its use further improved the safety of the newly introduced neuromuscular blocking agents (NMBAs) by allowing positive pressure ventilation. The last three decades have been witness to a significant increase in the number of NMBAs introduced into clinical care in an attempt to reduce the side effect profile, decrease their onset time for rapid management of the airway, shorten their duration of action,
Correspondence: Sorin J Brull

Department of Anesthesiology, Mayo Clinic College of Medicine, 4500 San

Pablo Road, Jacksonville, FL 32224, USA

Tel + I 904956333 |

$\mathrm{Fax}+\mathrm{I} 9049563332$

Email sjbrull@comcast.net 
and hasten their rapid recovery. In other words, numerous attempts have been made to develop the "perfect" muscle relaxant. $^{4}$

To some limited extent, the search for this "perfect" agent has been successful, although no current NMBA possesses all of the qualities of the ideal agent. Succinylcholine is rapid in onset, reliable in producing good intubating conditions, and relatively short in duration of action. Unfortunately, its many side effects limit its usefulness in some clinical situations and age groups. Rocuronium in large doses is also rapid in onset, and does not have some of the side effects (hyperkalemia, myalgia, malignant hyperthermia triggering) that limit the use of succinylcholine. Rocuronium, however, has a long and unpredictable duration of action after administration of large doses required for rapid sequence intubation, thus introducing a different set of patient safety concerns in those patients in whom mask ventilation and tracheal intubation are difficult or impossible. Equally problematic is the continued occurrence of residual weakness (the so-called "residual curarization") in patients who receive NMBAs, despite administration of adequate doses of reversal agents and even in patients deemed "fully recovered" by clinicians. In fact, residual paralysis continues to be reported, despite the change in the definition of "adequate recovery" from a train-of-four (TOF) ratio of 0.70 to the current TOF ratio value of $0.90 .5,6$

The literature is replete with case reports and clinical studies that have attempted to delineate the frequency with which residual neuromuscular effects are still present in postoperative patients following tracheal extubation. Recent reports $^{7-10}$ have documented that residual paralysis in the postoperative period is not benign: 8 of 7,459 patients $(0.1 \%)$ required emergent tracheal reintubation in the postoperative care unit (PACU) for respiratory insufficiency after tracheal extubation in the operating room. ${ }^{7}$ Clearly, a considerable number of patients continue to be at significant risk of morbidity and mortality.

It is thus clear that despite advances in the pharmacology of NMBAs, our current understanding of the need for perioperative neuromuscular monitoring of pharmacologic reversal is inadequate. Part of this limitation is due to the mechanism of action of classic reversal agents: by blocking acetylcholinesterases, traditional reversal agents allow an increase in the concentration of acetylcholine (ACh) at the neuromuscular junction, which then competes effectively (in most, but not all, cases) with the nondepolarizing muscle relaxant for the post-synaptic receptor recognition sites. The increase in the concentration of $\mathrm{ACh}$ at the neuromuscular junction, however, is limited by the amount of ACh that is degraded by acetylcholinesterases. Once the enzymes are inhibited maximally (and ACh is no longer degraded), the concentration of $\mathrm{ACh}$ at the neuromuscular junction reaches a maximum. In those cases in which this maximal concentration of $\mathrm{ACh}$ is still insufficient to compete effectively with the nondepolarizing muscle relaxant, the competition for receptor binding favors the relaxant, and neuromuscular block ensues.

Some depolarizing agents (eg, succinylcholine), as well as nondepolarizing muscle relaxants (eg, mivacurium), are naturally metabolized by plasma cholinesterases. In patients who have atypical plasma cholinesterases, the metabolism of these drugs is markedly prolonged. However, intravenous administration of human cholinesterase results in rapid reversal of neuromuscular block. ${ }^{11,12}$

Another potential mechanism that is more efficient in terminating the effects of NMBAs at the neuromuscular junction is the very rapid, nonenzymatic breakdown of some NMBAs that occurs in the presence of naturally occurring amino acids such as cysteine and glutathione. ${ }^{13}$ The prototype of this kind of amino acid is cysteine, which can be used to very rapidly terminate the neuromuscular blocking action of a new class of relaxants, the asymmetric mixed-onium chlorofumarates gantacurium (GW280430A, also known as AV430A) ${ }^{14}$ and AV002 (CW002). ${ }^{15}$ These compounds have undergone initial animal testing (gantacurium), or are scheduled to start testing in 2009 (AV002).

More efficient mechanisms for termination of the actions of nondepolarizing agents would constitute a significant advance in the pharmacology of muscle relaxants and the safety of clinical care. Conceptually, the direct inhibition of the NMBA activity at the effect site is a much more efficient mechanism of reversal, rather than reliance on ACh competition for receptor recognition sites. This proposed mechanism was used to develop a new class of NMBA reversal agents: the selective relaxant binding agent (SRBA). ${ }^{16}$ The prototype of this selective reversal agent is sugammadex.

\section{Human plasma cholinesterase Pharmacology}

Cholinesterases are enzymes that catalyze the hydrolysis of the neurotransmitter acetylcholine (ACh). There are two types of cholinesterases: the acetylcholinesterase (AChE, also known as red blood cell cholinesterase), whose main substrate is ACh; and pseudocholinesterase (also called plasma cholinesterase or butyrylcholinesterase $[\mathrm{BChE}]$ ), whose main substrate is butyrylcholine. In humans, the absolute level (quantity) and activity (quality) of plasma cholinesterases are 
determined by several genetic variations, leading to a large number of genotypes and phenotypes. ${ }^{17,18}$ Human BChE has been sequenced, and has been shown to contain four identical subunits (tetramer); each subunit contains 574 amino acids, and the tetramer has a total weight of $342,000 \mathrm{Da} .{ }^{19} \mathrm{BChE}$ is synthesized in the liver.

\section{Pseudocholinesterase deficiency}

A genetically inherited abnormality most common in people of European descent, pseudocholinesterase deficiency results in pseudocholinesterases (BChE) with abnormally slow ability to metabolize exogenous choline esters. The condition results in abnormally prolonged action of drugs that undergo hydrolysis of choline esters: succinylcholine, mivacurium, procaine, and cocaine. ${ }^{20}$

Acquired cases of cholinesterase deficiency usually result in a very similar clinical picture as the hereditary disease. Some of the causes of acquired pseudocholinesterase deficiency due to low cholinesterase activity include certain physiologic conditions (extremes of age, pregnancy); chronic infections (tuberculosis); alcohol abuse and liver disease (low hepatic synthetic function); extensive burn injury; malnutrition; renal failure and uremia; malignancy; and iatrogenic causes (plasmapheresis; organophosphate poisoning, echothiophate ophthalmic drops; anticholinesterase inhibitor therapy; monoamine oxidase inhibitors; glucocorticoids, contraceptive therapy).

\section{Antagonism of neuromuscular block}

In patients with acquired or hereditary pseudocholinesterase deficiency, the metabolic hydrolysis of succinylcholine and mivacurium are greatly impaired, resulting in prolonged muscle paralysis (4-8 hours). Human plasma cholinesterase administration has been shown to significantly decrease the duration of succinylcholine and mivacurium block (5-10 min and $30 \mathrm{~min}$, respectively) in these patients. ${ }^{11,21}$

\section{Pharmacokinetics and pharmacodynamics}

In normal patients receiving succinylcholine, approximately $90 \%-95 \%$ of the intravenous dose will be hydrolyzed in the plasma before reaching the neuromuscular junction, resulting in a short (4-10 $\mathrm{min})$ duration of action. In patients with pseudocholinesterase deficiency, most of the administered succinylcholine will not be metabolized and will reach the neuromuscular junction, resulting in markedly prolonged (4-8 hours) neuromuscular block. Mivacurium is also metabolized by $\mathrm{BChE}$ at a rate that is approximately $70 \%-75 \%$ of the rate of succinylcholine metabolism. ${ }^{22}$ In patients phenotypically heterozygous for pseudocholinesterase deficiency who received mivacurium, the duration of neuromuscular block, defined as return of TOF ratio to $>0.7$, was prolonged $(30 \mathrm{~min}) .{ }^{23}$ In patients homozygous for atypical cholinesterase, the recovery was even longer, 30-60 min. ${ }^{21}$ In phenotypically normal patients, the duration of action of mivacurium can be predicted based on the patients' cholinesterase activity; thus, in patients with $\mathrm{BChE}$ activity below the normal range, recovery from mivacurium is slightly prolonged. ${ }^{24}$

When administered intravenously to patients homozygous for the atypical gene for plasma cholinesterase, the halflife of $\mathrm{BChE}$ is approximately 11 days; it has a volume of distribution of $14 \%-18 \%$ of body weight. ${ }^{25}$

\section{Treatment}

Human plasma cholinesterase has been available commercially for well over 30 years. ${ }^{26}$ Human BChE can be purchased in 5- and 10-unit lots, where one unit corresponds to the amount of enzyme that will hydrolyze one micromole of butyrylcholine substrate per minute at $37^{\circ} \mathrm{C}$ and $\mathrm{pH}$ of 8.0. As of 2009 , the cost for a 5-unit dose was $\$ 220$, and for the 10-unit dose it was $\$ 400$ (BioPur AG, Bubendorf, Switzerland). The highly purified native proteins are reported to be free from potential contaminants such as hepatitis virus or HIV, and no hypersensitivity reactions have been described. ${ }^{12}$

Since cocaine is metabolized by cholinesterases, individuals with pseudocholinesterase deficiency may be at increased risk of toxic reactions, arrhythmias, myocardial infarction, stroke and death associated with recreational use of cocaine. ${ }^{27}$ In laboratory animals, the prophylactic administration of human plasma cholinesterase protects against the convulsive and lethal effects of cocaine overdose. ${ }^{28}$

Prophylactic transfusion of fresh frozen plasma can sometimes improve the patient's own plasma cholinesterase activity. However, the risk of transfusion-related infection outweighs the benefits and is not recommended. Administration of cholinesterase inhibitors such as neostigmine is controversial, as the effect is variable, improvement (if any) is transient, and may be followed by an increase in the degree of neuromuscular block. ${ }^{29}$ In the absence of readily available human plasma cholinesterase, mechanical ventilatory support (with analgesia and amnesia) is the recommended treatment until the return of spontaneous respiratory muscle function.

In patients with normal cholinesterase activity levels, the administration of human plasma cholinesterase results in reversal of mivacurium-induced block that is similar to that induced by edrophonium. However, the combination of 
edrophonium and human plasma cholinesterase significantly accelerates recovery of mivacurium-induced block. ${ }^{30}$ When comparing the anticholinesterase neostigmine with human plasma cholinesterase for mivacurium and succinylcholine reversal, neostigmine was an incomplete reversal drug, and at pharmacologic concentrations, it actually inhibited the effects of plasma cholinesterase. ${ }^{29}$

\section{Cysteine}

\section{Pharmacology}

A semi-essential (or conditionally essential) amino acid, cysteine can be synthesized from the essential amino acid methionine and the nonessential amino acid serine by the process of trans-sulfuration ${ }^{31}$ (Figure 1). In this pathway, cysteine is formed when methionine donates the sulfur to serine. Cysteine has two stereoisomers that are not superimposable mirror images (enantiomers): the L- and the D-enantiomers. Of the two, the L-cysteine enantiomer acts as a precursor amino acid for the synthesis of several proteins such as coenzyme A and $\gamma$-glutamylcysteinylglycine. The extent of racemization of L-amino acid residues to the D-enantiomers in food proteins increases with $\mathrm{pH}$, time, and temperature. ${ }^{32}$ Since D-amino acids are, in general, deleterious, D-cysteine (whether ingested or formed in the body) imposes a metabolic burden on the organism and could therefore be considered toxic. ${ }^{32}$

L-cysteine and its oxidized counterpart, cystine, are rate-limiting precursors in the synthesis of glutathione. In fact, cysteine is stored in the body as glutathione (which may be hydrolyzed to generate cysteine if needed), which may explain the low tissue concentration of cysteine. ${ }^{33}$ Glutathione also serves as a means for transporting cysteine to extrahepatic tissues. ${ }^{33}$

\section{Safety}

L-cysteine is a sulfate donor in detoxification reactions. ${ }^{34}$ Because of its participation in detoxification, it has important neuroprotective roles. ${ }^{35}$ Another mechanism of neuroprotection by L-cysteine is the interference it provides to the entry of potentially injurious heavy metal ions across the blood-brain barrier. ${ }^{36}$ Despite these neuroprotective effects, however, L-cysteine can also be neurotoxic in high concentrations. Administration of exogenous L-cysteine is excitatory, and its neurotoxic effects have been implicated in several neurological disorders such as Parkinson's, Alzheimer's, amyotrophic lateral sclerosis (ALS), and in organic brain injury associated with hypoxia, ischemia, and hypoglycemia..$^{34,37-39}$

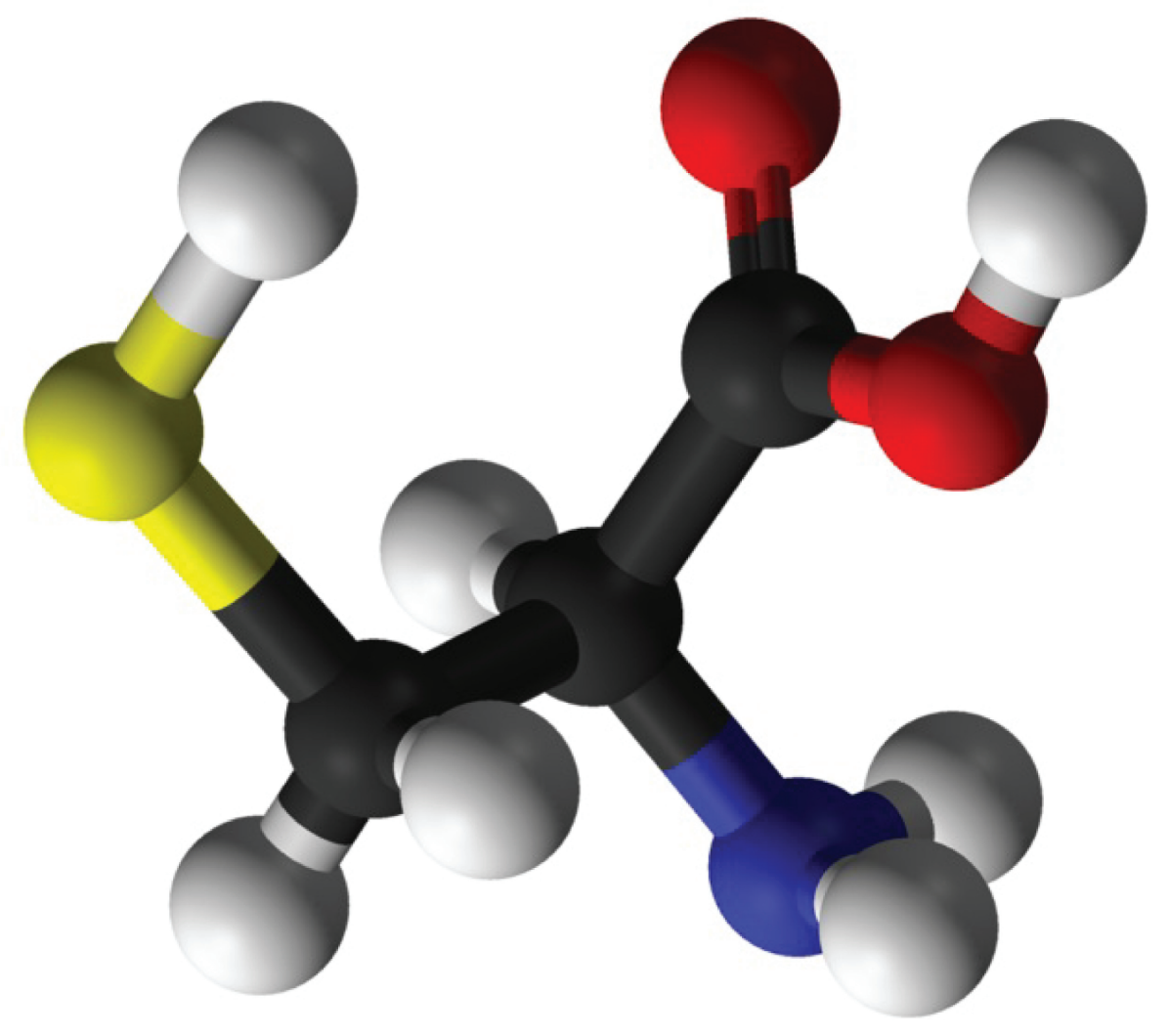

Figure I L-cysteine. 
There are several putative mechanisms of L-cysteine toxicity; during ischemic brain damage, L-cysteine is released in the extracellular fluid from glial cells by a mechanism that involves $\gamma$-glutamyltransferase $\left(\gamma\right.$-GT).$^{40}$ This mechanism may involve the breakdown of glutathione by $\gamma$-GT, in addition to L-cysteine release from cells, leading to excitotoxic effects. The second mechanism may involve the interaction of L-cysteine with the N-methyl-D-aspartate (NMDA) receptors, which results in NMDA receptor activation and massive influx of $\mathrm{Ca}^{2+}$. The prolonged NMDA receptor overexcitation and massive secondary release of $\mathrm{Ca}^{2+}$ from intracellular stores leads to cell death. ${ }^{41}$ L-cysteine thus enhances the glutamate- and NMDA-evoked neuronal influx of $\mathrm{Ca}^{2+}$, leading to destruction of neurons when L-cysteine is administered orally in high doses to laboratory animals with underdeveloped blood-brain barriers (such as infant mice). ${ }^{42}$

The third putative mechanism may involve oxygen free radical generation. ${ }^{43}$ The excess oxygen free radicals may then cause overactivation of NMDA receptors via lipid peroxidation. Additionally, the neurotoxicity of L-cysteine may be mediated by the increased extracellular concentration of glutamate as a result of the inhibition of glutamate neuronal reuptake by L-cysteine. ${ }^{44}$ Because L-cysteine is metabolized to toxic oxidized products such as S-sulfocysteine and cysteate, such products act at glutamate receptors and mediate neurotoxic effects. ${ }^{45}$ Subcutaneous administration of 0.5 to $1.5 \mathrm{mg} / \mathrm{g}$ body weight of L-cysteine to $4-$ to 6-day-old mice (this dose is approximately 50-75 times greater than the reversal dose of $10-20 \mathrm{mg} / \mathrm{kg}$ ) resulted in severe hypoglycemia and central neural damage, which was glucose-reversible. ${ }^{46}$ It was thus hypothesized that cysteine-induced neurotoxicity was linked to hypoglycemia. Excess dietary L-cysteine ( $30 \mathrm{gm} / \mathrm{kg}$ for three days) also caused lethal metabolic acidosis in chicks, despite being fed an otherwise nutritionally adequate meal diet. ${ }^{47}$

Finally, L-cysteine interacts with catecholamines (dopamine, norepinephrine, epinephrine) and may result in covalent binding of catecholamines to cysteine residues. L-cysteine thus forms neurodestructive cysteinylcatechols such as cysdopac ${ }^{48}$ which may inhibit mitochondrial respiration. ${ }^{49}$ For a comprehensive review on the mechanisms of cysteine-induced neurotoxicity, see Janaky and colleagues ${ }^{49}$ Despite the multiple potential side effects, L-cysteine is added to total parenteral nutrition solutions ( $\sim 300 \mathrm{mg}$ of cysteine/L) to enhance calcium and phosphate solubility, because cysteine lowers the $\mathrm{pH}$ (cysteine $\mathrm{pH}$ is 1.0) of the solution. Use of these solutions, however, has been associated with the development of acidosis in infants..$^{50}$
In view of the multiple putative mechanisms by which L-cysteine could be neuroexcitatory and neurotoxic, there are still many unanswered questions regarding the safety of giving humans exogenous cysteine in doses required for adequate antagonism of the new chlorofumarate muscle relaxants gantacurium and/or AV002. These questions would be particularly applicable in clinical scenarios such as trauma, neurosurgery, obstetrics, to name a few, as well as specific patient populations such as patients at extremes of age, those with diabetes, treated hypertensive patients, or those with pre-existing neurodegenerative disease. Clearly, before the introduction of cysteine into clinical use as a reversal agent (antagonist of mixed-onium chlorofumarates gantacurium and AV002), significant preliminary work needs to be done. Absorption, distribution, metabolism and excretion (A.D.M.E.) data from animals will need to be investigated as part of the New Drug Application process.

\section{Antagonism of neuromuscular block}

In laboratory animals (Rhesus monkeys), doses of gantacurium eight times greater than those required for $95 \%$ depression of the neuromuscular response $\left(\mathrm{ED}_{95}\right)$ have a duration of action of approximately 14 minutes. Cysteine reversal $(10 \mathrm{mg} / \mathrm{kg})$ results in return of complete neuromuscular function in 1-2 min. ${ }^{13}$ Similarly, cysteine $(50 \mathrm{mg} / \mathrm{kg}$ dose) will decrease the duration of neuromuscular block of AV002 from $30 \mathrm{~min}$ to $2-3 \mathrm{~min}^{13}$

\section{Pharmacokinetics: animal data}

Cysteine, with a reported half-life of 1-2 hours, given to male Rhesus monkeys accelerated the recovery times from profound neuromuscular blockade induced by AV002. ${ }^{51}$ Cysteine $100 \mathrm{mg} / \mathrm{kg}$ given to four dogs anesthetized with isoflurane/nitrous oxide produced a brief ( $2-3 \mathrm{~min}$ ) decline in mean arterial blood pressure, followed by a sustained increase. ${ }^{52}$ This pattern was accompanied by minimal changes in heart rate and systemic vascular resistance, stroke volume, left ventricular ejection fraction, and left ventricular inotropy (assessed as change in pressure/change in time normalized to left ventricular end-diastolic volume). The authors noted that the hemodynamic effects reported were consistent with both direct and reflex responses in combination with a centrally-mediated vasopressin release. ${ }^{52}$ Doses ranging from 20 to $50 \mathrm{mg} / \mathrm{kg}$ of cysteine resulted in minimal changes in mean arterial blood pressure and heart rate. Only a $100 \mathrm{mg} / \mathrm{kg}$ dose of cysteine resulted in a $14.6 \%$ increase in mean arterial pressure and a $5.2 \%$ decrease in heart rate. ${ }^{53}$ 
In studies of reversal of neuromuscular block in Rhesus monkeys, adult animals received cysteine (50-200 mg/kg) every 4-6 weeks for over three years. There have been no changes in general physical exam, body weight, or serum chemistries (hematology, liver or kidney function tests). Similarly, there have been no reports of organ damage or histopathologic changes in adult laboratory rats and dogs given intravenous cysteine (studies performed at Charles River Laboratories in Shrewsbury, MA.; IND report submitted to FDA, J. J. Savarese, MD, personal communication).

\section{Sugammadex}

\section{Pharmacology}

Sugammadex is a synthetic $\gamma$-cyclodextrin, and the first compound in a new class of neuromuscular reversal drugs called SRBAs. ${ }^{16,54-56}$ Cyclodextrins are cyclic dextrose units joined through 1-4 glycosyl bonds, and are produced from starch or starch derivates using cyclodextrin glycosyltransferase. The three most common cyclodextrins consist of six, seven, or eight cyclic oligosaccharides and are named $\alpha$-, $\beta$-, or $\gamma$-cyclodextrin, respectively. Cyclodextrins can be formed naturally from bacteria, or they can be manufactured synthetically.

The molecular characteristics of unmodified $\gamma$-cyclodextrin (A) and modified $\gamma$-cyclodextrin (sugammadex) (B) are shown in Figure 2. ${ }^{56}$ The cyclodextrin three-dimensional structure resembles a doughnut, in which the cavity is hydrophobic and the exterior is hydrophilic because of the presence of charged hydroxyl groups. Hydrophobic interactions were designed to trap the drug into the cyclodextrin cavity, resulting in the formation of a very stable, water-soluble guest-host complex.

Compared with $\alpha$-and $\beta$-cyclodextrins, $\gamma$-cyclodextrin is designed to better fit the steroidal muscle relaxant molecule; sugammadex, in particular, has a larger lipophilic cavity (7.5-8.3 $\AA$ diameter) than the $\alpha$ - and $\beta$-cyclodextrins (whose internal cavity diameter is less than $6.5 \AA$ ). This cavity size is better suited to incorporate (encapsulate) rocuronium and vecuronium molecules, whose width is approximately $7.5 \AA .{ }^{56}$ For sugammadex, the specificity toward steroidal muscle relaxants was further increased by the addition of eight polar hydroxyl side chains. This modification allowed the four hydrophobic steroidal rings of rocuronium (or vecuronium) to be better accommodated within the hydrophobic cavity of the sugammadex molecule, while the negatively charged carboxyl groups at the end of the eight side chains allow enhanced electrostatic binding to the positively charged quaternary nitrogen of rocuronium. ${ }^{16,56}$
A

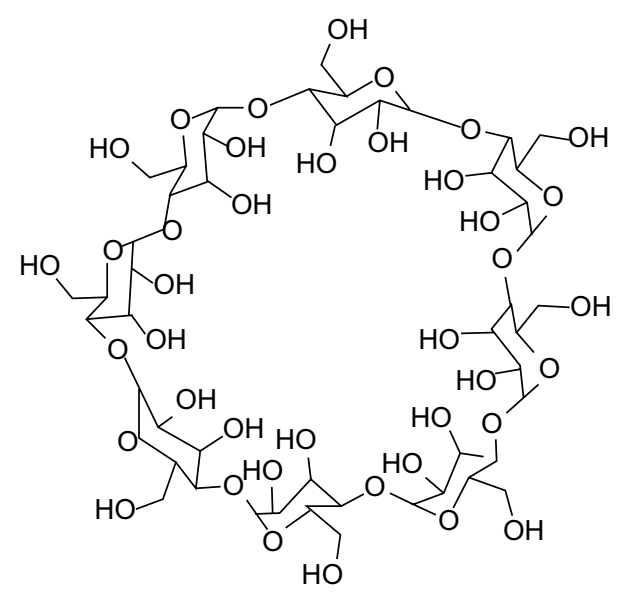

B

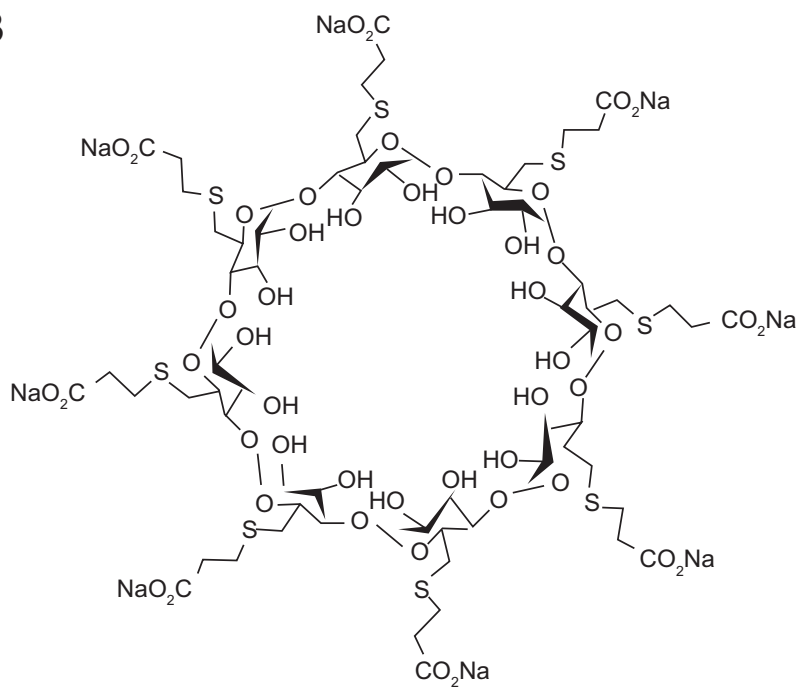

Figure 2 Cyclodextrin, sugammadex. A) Unmodified $\gamma$-cyclodextrin. B) Modified $\gamma$-cyclodextrin.

Additionally, the repellent forces of the negatively charged carboxyl groups keep the cavity open and maintain molecular structural integrity.

The resulting sugammadex compound has a molecular weight of 2,178 Da; it is highly water-soluble and the aqueous solution of sugammadex has a $\mathrm{pH}$ of approximately 7.5 , with an osmolality of 300-500 $\mathrm{mOsmol} / \mathrm{kg}$. Because of the intermolecular (van der Waals) forces, the thermodynamic (hydrogen) bonds, and the hydrophobic interactions, sugammadex forms very tight complexes at a 1:1 ratio with steroidal neuromuscular blocking agents (rocuronium $>$ vecuronium $>>$ pancuronium). ${ }^{16,54-56}$ The sugammadex-rocuronium complex has a very high association rate (an association constant of $10^{7} \mathrm{M}^{-1}$ as determined by isothermal titration calorimetry) and a very low dissociation rate. It is estimated that only one out of every 25 million sugammadex-rocuronium complexes dissociates. 
Sugammadex has a different mechanism of pharmacologic reversal than the anticholinesterase agents, and thus exerts no effect on any receptor system in the body. Because of this, administration of sugammadex does not necessitate the co-administration of anticholinergic drugs, thus eliminating their undesirable adverse effects. In addition, the unique and selective mechanism of reversal by encapsulation is independent of the depth of neuromuscular block or the degree of spontaneous recovery; thus, reversal can be accomplished at any depth of neuromuscular block.

\section{Pharmacodynamics}

Because of its molecular structure, sugammadex may interact with drugs other than the intended steroidal nondepolarizing muscle relaxants. Among the compounds that may affect the efficacy of sugammadex are toremifene, flucloxacillin and fusidic acid. Toremifene may displace rocuronium because of its high affinity for sugammadex. Thus, administration of toremifene within 24 hours of surgery may delay reversal of neuromuscular block. ${ }^{57}$ For the intravenous administration of flucloxacillin and fusidic acid, the displacement of vecuronium or rocuronium from sugammadex may also result in delay in recovery of neuromuscular function, but these two drugs should be avoided only for six hours postoperatively. ${ }^{57}$ For all these drugs, a period of surveillance to exclude potential delay in reversal and occurrence of respiratory compromise is recommended. The interaction of sugammadex with oral hormonal contraceptives has the effect of one missed daily dose (for either the combined or progestogen-only contraceptive).

In general, sugammadex has not been reported to interfere with most laboratory tests; the possible exceptions are serum progesterone assay and some coagulation parameters (activated partial thromboplastin time, prothrombin time/international normalized ratio). This interference was observed in plasma samples in which the concentration of sugammadex was in the same range as that obtained after a dose of $16 \mathrm{mg} / \mathrm{kg}$. The clinical relevance of these findings is uncertain, however, as this has not been studied in patients. ${ }^{57}$

\section{Antagonism of neuromuscular block}

The reversal activity of sugammadex is selective for steroidal neuromuscular blocking agents. Sugammadex has no affinity for isoquinolinium agents such as mivacurium or atracurium. ${ }^{58}$ Sugammadex, used in recommended doses of $2-16 \mathrm{mg} / \mathrm{kg}$, is capable of reversal (defined as return of TOF ratio to $\geq 0.9$ ) of any depth of neuromuscular block induced by rocuronium or vecuronium within three minutes. ${ }^{59-61}$ Intravenous administration of sugammadex results in rapid removal of free rocuronium or vecuronium molecules from the plasma, creating a concentration gradient that favors the movement of the remaining unbound molecules away from the neuromuscular junction and into the plasma. Here, the unbound rocuronium or vecuronium molecules are encapsulated by the remaining unbound sugammadex molecules. At the same time, the unbound (as well as the complexed) sugammadex molecules also enter the extracellular volume along the concentration gradient and form new complexes with the unbound rocuronium or vecuronium. Therefore, the neuromuscular blocking actions of the unbound neuromuscular agents are terminated rapidly because of their diffusion away from the neuromuscular junction back into the plasma. This results in an increase in the total plasma concentration of rocuronium (both unbound and bound to sugammadex $)^{62}$ or vecuronium.

The efficacy of reversal with sugammadex has been studied in three clinical conditions that mirror the recommended dose ranges: 1) if reversal of shallow block (defined as spontaneous recovery to reappearance of the second twitch, $\mathrm{T}_{2}$, of the TOF) is desired, a dose of $2 \mathrm{mg} / \mathrm{kg}$ is recommended; 2) for reversal of deep block (defined as spontaneous recovery to at least 1-2 post-tetanic counts, PTC $_{1-2}$ ), a dose of $4 \mathrm{mg} / \mathrm{kg}$ is recommended; and 3) for "rescue" in the scenario of a large dose administration when there is no evidence of any spontaneous recovery in the "cannot intubate-cannot ventilate" setting, a dose of $16 \mathrm{mg} / \mathrm{kg}$ is recommended. ${ }^{57}$ These doses of sugammadex were used for subsequent clinical trials that formed the basis for approval by the European Medicines Agency (EMEA).

Based on the published tolerance intervals $(97.5 \%$ confidence level), a dose of $2 \mathrm{mg} / \mathrm{kg}$ of sugammadex for reversal of shallow block (return of $\mathrm{T}_{2}$ ) will result in complete reversal (TOF > 0.9) in 90\% of patients within three minutes after rocuronium administration, and within 5.9 min after vecuronium administration. ${ }^{63}$ Based on the same tolerance intervals (97.5\% confidence level), a dose of $4 \mathrm{mg} / \mathrm{kg}$ of sugammadex for reversal of deep block (administered at $\mathrm{PTC}_{1-2}$ ) will result in complete reversal (TOF $>0.9$ ) in $90 \%$ of patients within 3.9 min after rocuronium administration (no confidence intervals were calculated for vecuronium at this deep level of block). ${ }^{63}$ Finally, for immediate reversal of block (within 3-5 minutes of administration of $1.2 \mathrm{mg} / \mathrm{kg}$ of rocuronium), the mean time for complete spontaneous recovery was 122.5 minutes (range, $87-156$ minutes), while a dose of sugammadex of $16 \mathrm{mg} / \mathrm{kg}$ resulted in complete recovery within a mean of $1.6 \mathrm{~min}$ (range $0.7-6.9 \mathrm{~min}$ ) (Tables 1, 2). ${ }^{63}$ 
Table I Rocuronium administration: summary of time (in minutes) from administration at shallow block (reappearance of $\mathrm{T}_{2}$ ) and deep block $\left(\mathrm{PTC}_{\mathrm{L}_{-2}}\right.$ ) until recovery (TOF $\left.>0.9\right)$

\begin{tabular}{|c|c|c|c|c|}
\hline & Placebo & $2.0 \mathrm{mg} / \mathrm{kg}$ & $4 \mathrm{mg} / \mathrm{kg}$ & $8 \mathrm{mg} / \mathrm{kg}$ \\
\hline \multicolumn{5}{|l|}{ Shallow block } \\
\hline$n$ & 25 & 38 & 39 & - \\
\hline Mean $( \pm S D)$ & $60.0(38.8)$ & I.6 (0.7) & I. $4(0.7)$ & - \\
\hline Range & $15-153$ & $0.7-4.8$ & $0.7-4.8$ & - \\
\hline \multicolumn{5}{|l|}{ Deep block } \\
\hline$n$ & 3 & 34 & 31 & 34 \\
\hline Mean $( \pm S D)$ & $35.6(9.0)$ & $3.6(2.6)$ & $1.8(1.0)$ & I.3 (0.4) \\
\hline Range & $30-46$ & $1.1-15.2$ & $0.8-4.5$ & $0.6-2.4$ \\
\hline
\end{tabular}

Abbreviations: PTC, post-tetanic counts; SD, standard deviation; TOF, train-of-four.

With profound blockade induced by large doses of rocuronium or vecuronium, larger doses of sugammadex $(8-16 \mathrm{mg} / \mathrm{kg})$ are required for adequate and rapid recovery. For instance, when comparing the speed of recovery from $1.2 \mathrm{mg} / \mathrm{kg}$ of rocuronium followed three minutes later by $16 \mathrm{mg} / \mathrm{kg}$ of sugammadex with the speed of spontaneous recovery from $1.0 \mathrm{mg} / \mathrm{kg}$ of succinylcholine, the total time from the administration of rocuronium until recovery of the TOF to $\geq 0.9$ was less than that needed for a similar degree of spontaneous recovery from the succinylcholineinduced block. ${ }^{61}$

Since all drugs behave in a dose-response manner, ${ }^{64}$ rare instances of re-paralysis ("recurarization") have been reported in human and animal studies after administration of inadequate doses $(<2 \mathrm{mg} / \mathrm{kg})$ of sugammadex..$^{58-60,62,65-67}$ A temporary decrease in TOF response was thus observed after reversal of muscle relaxation with a small dose $(0.5 \mathrm{mg} / \mathrm{kg})$

Table 2 Vecuronium administration: summary of time (in minutes) from administration at shallow block (reappearance of $T_{2}$ ) and deep block $\left(\mathrm{PTC}_{1-2}\right.$ ) until recovery (TOF $\left.>0.9\right)$

\begin{tabular}{|c|c|c|c|c|}
\hline & Placebo & $2.0 \mathrm{mg} / \mathrm{kg}$ & $4 \mathrm{mg} / \mathrm{kg}$ & $8 \mathrm{mg} / \mathrm{kg}$ \\
\hline \multicolumn{5}{|c|}{ Shallow block } \\
\hline $\mathrm{n}$ & 19 & 21 & 26 & 4 \\
\hline Mean $( \pm S D)$ & $74.2(26.8)$ & $2.8(1.3)$ & $2.3(1.5)$ & I.4 (0.5) \\
\hline Range & $27-|4|$ & I.3-7.I & I.0-8.5 & $0.8-2.0$ \\
\hline \multicolumn{5}{|l|}{ Deep block } \\
\hline $\mathrm{n}$ & - & 21 & 18 & 20 \\
\hline Mean $( \pm S D)$ & - & $12.4(32.0)$ & $3.2(2.8)$ & $2.3(2.7)$ \\
\hline Range & - & $1.5-136.1$ & $0.9-11.7$ & $0.7-13.5$ \\
\hline
\end{tabular}

Abbreviations: PTC, post-tetanic counts; SD, standard deviation; TOF, train-of-four. of sugammadex administered 42 minutes after $0.9 \mathrm{mg} / \mathrm{kg}$ of rocuronium, indicating there were insufficient numbers of sugammadex molecules available to encapsulate all existing rocuronium molecules. ${ }^{68}$

\section{Pharmacokinetics and metabolism}

Sugammadex has no affinity for binding to plasma proteins. ${ }^{60,65,69}$ When administered to volunteers who had not received a neuromuscular blocking agent, doses of $0.1-8.0 \mathrm{mg} / \mathrm{kg}$ of sugammadex had a clearance rate of $88 \mathrm{~mL} /$ minute, an elimination half-life of 1.8 hours, and a volume of distribution of 11-14 L. ${ }^{65,70}$ Approximately 75\% of the dose was eliminated renally. Between $59 \%$ and $80 \%$ of the sugammadex dose is excreted renally in the first 24 hours after administration. ${ }^{65}$ The kinetics of sugammadex appeared to be linear when the sugammadex dose was increased from 0.1 to $8.0 \mathrm{mg} / \mathrm{kg} .{ }^{65}$

In the absence of sugammadex, rocuronium is eliminated mainly by biliary excretion $(>75 \%)$ and to a lesser degree by renal and fecal routes. ${ }^{71}$ In contrast, the plasma clearance of sugammadex alone is approximately one third that of rocuronium alone. ${ }^{72}$ Because of the soluble nature of the sugammadex-rocuronium complex, urinary excretion of the complex is the major route for the elimination of the complexed rocuronium ( $65 \%-97 \%$ of the administered dose is recovered in urine). ${ }^{65,72}$

Metabolism of sugammadex is at most very limited, and the drug is thus eliminated in the urine mostly unchanged. In patients with substantial renal impairment, compared with healthy subjects, the clearance of sugammadex and rocuronium was decreased by a factor of 17 and 4, respectively, and the elimination half-life was increased by a factor of 15 and 2.5, respectively. ${ }^{73}$ Dialysis for removal of sugammadex and rocuronium from the plasma is not consistently effective. Therefore, it has been recommended that sugammadex be avoided in patients with a creatinine clearance of $<30 \mathrm{~mL} /$ minute.

Sugammadex is not metabolized by the liver, so it has not been evaluated specifically in patients with hepatic impairment; however, caution is recommended in the use of sugammadex in patients with liver failure. ${ }^{57}$ The pharmacokinetic response to sugammadex in elderly patients depends mostly on adequate renal function, and no changes in the metabolism or excretion of sugammadex are expected based solely on patient age.

A total of 77 patients with pulmonary disease such as asthma, bronchitis and chronic obstructive pulmonary disease, tolerated the administration of sugammadex without significant problems. ${ }^{74}$ However, bronchospasm was reported 
twice in patients with asthma, both in the $4 \mathrm{mg} / \mathrm{kg}$ group, and both required treatment, but had no sequelae. ${ }^{74}$ Several other detailed articles have been published recently on sugammadex..$^{61,75}$

\section{Safety}

The safety of sugammadex has been evaluated based on an integrated safety database of approximately 1,700 patients and 120 volunteers. The most commonly reported adverse reaction, dysgeusia (metal or bitter taste), was generally reported after doses of $32 \mathrm{mg} / \mathrm{kg}$ of sugammadex or higher. In a few individuals, allergic-like reactions (ie, flushing, erythematous rash) following sugammadex were reported. In one of these individuals, a mild allergic reaction was confirmed. ${ }^{57}$

Several studies have investigated the effects of sugammadex on the QTc interval. All of the published data to this point suggest that sugammadex does not significantly prolong the QTc interval. Prolongation was defined as an absolute QTc value $>500 \mathrm{msec}$, or an increase in baseline QTc of at least $60 \mathrm{msec}^{57}$ There also was no evidence that sugammadex may predispose patients to QTc prolongation when sugammadex was administered in conjunction with drugs known for their propensity to prolong the QTc (such as propofol and sevoflurane).$^{57}$ Even in a subgroup of patients with severe heart disease, sugammadex did not induce QTc prolongation. ${ }^{76}$

There have been no reports of clinically significant effects of sugammadex on hemodynamic variables (blood pressure, heart rate), respiration, or thermoregulation. ${ }^{57}$

Common (incidence 1\%-10\%) adverse effects are similar for sugammadex and placebo. They include anesthetic complications (movement, coughing, grimacing, or suckling on the tracheal tube). While sugammadex has been approved by EMEA for clinical use in several European countries last summer, the US Food and Drug Administration issued a "not approvable" letter (August 2008), citing concerns about hypersensitivity and allergic reactions. It is hoped that additional clinical and safety data will soon become available from the European experience, and may influence the US Food and Drug Administration decisions on the approval of sugammadex.

\section{Conclusion}

Despite the significant advances in the chemistry of neuromuscular blocking agents, the promise of the "perfect" or "ideal" drug remains illusory. However, it is incontroversial that the significant improvements made in the last few decades in the pharmacology of relaxants and reversal agents have improved clinical care and patient safety. Even if we do not yet have a fast-onset, highly reliable, short duration, rapidly reversible, noncumulative nondepolarizing drug, the characteristics of the "perfect" drug are within reach. By combining the rapid onset of a drug like rocuronium (or gantacurium or AV002) with the fast reversal and stable hemodynamic profile of the selective reversal agent sugammadex (or cysteine and glutathione), the promise of rapid onset of block with rapid and reliable offset has become reality. And because reversal by both sugammadex and cysteine is independent of the depth of neuromuscular block, the morbidity associated with the "cannot-ventilate/ cannot-intubate" clinical scenario is avoided; moreover, the lack of disassociation of the rocuronium/sugammadex complex, and the lack of neuromuscular blocking potency of the chlorofumarates' break-down products, will ensure that the recurrence or persistence of residual weakness will become an oddity of the past.

\section{Disclosure}

Dr. Naguib has worked as a consultant on an ad hoc basis with Organon Pharmaceuticals (Roseland, New Jersey) and Avera Pharmaceuticals (San Diego, California). Dr. Brull has no conflict of interest to disclose.

\section{References}

1. Beecher HK, Todd DP. A study of the deaths associated with anesthesia and surgery: based on a study of 599, 548 anesthesias in ten institutions 1948-1952, inclusive. Ann Surg. 1954;140:2-35.

2. Bernstein AM, Koo HP, Bloom DA. Beyond the Trendelenburg position: Friedrich Trendelenburg's life and surgical contributions. Surgery. 1999;126:78-82.

3. Luckhaupt H, Brusis T. [History of intubation]. Laryngol Rhinol Otol (Stuttg). 1986;65:506-510.

4. Savarese JJ, Kitz RJ. Does clinical anesthesia need new neuromuscular blocking agents? Anesthesiology. 1975;42:236-239.

5. Ali HH, Utting JE, Nightingale DA, Gray C. Quantitative assessment of residual curarization in humans. Br J Anaesth. 1970;42:802-803.

6. Kopman AF, Yee PS, Neuman GG. Relationship of the train-of-four fade ratio to clinical signs and symptoms of residual paralysis in awake volunteers. Anesthesiology. 1997;86:765-771.

7. Murphy GS, Szokol JW, Marymont JH, Greenberg SB, Avram MJ, Vender JS. Residual neuromuscular blockade and critical respiratory events in the postanesthesia care unit. Anesth Analg. 2008;107: 130-137.

8. Cammu G, De Witte J, De Veylder J. Postoperative residual paralysis in outpatients versus inpatients. Anesth Analg. 2006;102:426-429.

9. Hayes AH, Mirakhur RK, Breslin DS, Reid JE, McCourt KC. Postoperative residual block after intermediate-acting neuromuscular blocking drugs. Anaesthesia. 2001;56:312-318.

10. Beard K, Jick H, Walker AM. Adverse respiratory events occurring in the recovery room after general anesthesia. Anesthesiology. 1986;64:269-272.

11. Viby-Mogensen J. Succinylcholine neuromuscular blockade in subjects homozygous for atypical plasma cholinesterase. Anesthesiology. 1981;55:429-434. 
12. Naguib M, Daoud W, el-Gammal M, Ammar A. Enzymatic antagonism of mivacurium-induced neuromuscular blockade by human plasma cholinesterase. Anesthesiology. 1995;83:694-701.

13. Savarese JJ, Belmont MR, Schad B, Van Ornum S. SAR of reversal of isoquinolinium fumarate and succinate diester NMBA's by cysteine/ glutathione [abstract]. Anesthesiology. 2007;107:A985.

14. Savarese JJ, Belmont MR, Cohn DL, Schad B, Van Ornum S. Some SAR among Isoquinolinium Fumarate Diesters Leading to the Identification of AV002 [abstract]. Anesthesiology. 2007;107:A386.

15. Sunaga H, Malhotra JK, Savarese JJ, Heerdt PM. Cardiovascular effects of cysteine used for reversal of novel neuromuscular blocking drugs in dogs [abstract]. Anesthesiology. 2008;109:A367.

16. Adam JM, Bennett DJ, Bom A. Cyclodextrin-derived host molecules as reversal agents for the neuromuscular blocker rocuronium bromide: synthesis and structure-activity relationships. J Med Chem. 2002;45:1806-1816.

17. Jensen FS, Viby-Mogensen J. Plasma cholinesterase and abnormal reaction to succinylcholine: twenty years' experience with the Danish Cholinesterase Research Unit. Acta Anaesthesiol Scand. 1995;39:150-156.

18. Massoulie J. The origin of the molecular diversity and functional anchoring of cholinesterases. Neurosignals. 2002;11:130-143.

19. Lockridge O, Bartels CF, Vaughan TA, Wong CK, Norton SE, Johnson LL. Complete amino acid sequence of human serum cholinesterase. J Biol Chem. 1987;262:549-557.

20. Maiorana A, Roach RB Jr. Heterozygous pseudocholinesterase deficiency: a case report and review of the literature. J Oral Maxillofac Surg. 2003;61:845-847.

21. Ostergaard D, Viby-Mogensen J, Rasmussen SN, Gatke MR, Varin F. Pharmacokinetics and pharmacodynamics of mivacurium in patients phenotypically homozygous for the atypical plasma cholinesterase variant: effect of injection of human cholinesterase. Anesthesiology. 2005;102:1124-1132.

22. Cook DR, Stiller RL, Weakly JN, Chakravorti S, Brandom BW, Welch RM: In vitro metabolism of mivacurium chloride (BW B1090U) and succinylcholine. Anesth Analg. 1989;68:452-456.

23. Ostergaard D, Viby-Mogensen J, Rasmussen SN, Gatke MR, Pedersen NA, Skovgaard LT. Pharmacokinetics and pharmacodynamics of mivacurium in patients phenotypically heterozygous for the usual and atypical plasma cholinesterase variants (UA). Acta Anaesthesiol Scand. 2003;47:1219-1225.

24. Ostergaard D, Ibsen M, Skovgaard L, Viby-Mogensen J: Plasma cholinesterase activity and duration of action of mivacurium in phenotypically normal patients. Acta Anaesthesiol Scand. 2002;46:679-683.

25. Ostergaard D, Viby-Mogensen J, Hanel HK, Skovgaard LT. Half-life of plasma cholinesterase. Acta Anaesthesiol Scand. 1988;32:266-269.

26. Stovner J, Stadskleiv K. Suxamethonium apnoea terminated with commercial serum cholinesterase. Acta Anaesthesiol Scand. 1976;20:211-215.

27. Jatlow P, Barash PG, Van Dyke C, Radding J, Byck R. Cocaine and succinylcholine sensitivity: a new caution. Anesth Analg. 1979;58: 235-238.

28. Hoffman RS, Morasco R, Goldfrank LR. Administration of purified human plasma cholinesterase protects against cocaine toxicity in mice. J Toxicol Clin Toxicol. 1996;34:259-266.

29. Yang HS, Goudsouzian N, Martyn JA. Pseudocholinesterase-mediated hydrolysis is superior to neostigmine for reversal of mivacuriuminduced paralysis in vitro. Anesthesiology. 1996;84:936-944.

30. Naguib M, Samarkandi AH, Bakhamees HS, Turkistani A, Alharby SW. Edrophonium and human plasma cholinesterase combination for antagonism of mivacurium-induced neuromuscular block. Br J Anaesth . 1996;77:424-426.

31. Rao AM, Drake MR, Stipanuk MH. Role of the transsulfuration pathway and of gamma-cystathionase activity in the formation of cysteine and sulfate from methionine in rat hepatocytes. J Nutr. 1990;120:837-845.

32. Friedman M. Formation, nutritional value, and safety of D-amino acids. Adv Exp Med Biol. 1991;289:447-481.
33. Stipanuk MH. Sulfur amino acid metabolism: pathways for production and removal of homocysteine and cysteine. Annu Rev Nutr. 2004;24:539-577.

34. Heafield MT, Fearn S, Steventon GB, Waring RH, Williams AC, Sturman SG. Plasma cysteine and sulphate levels in patients with motor neurone, Parkinson's and Alzheimer's disease. Neurosci Lett. 1990;110:216-220.

35. Miyamoto M, Murphy TH, Schnaar RL, Coyle JT. Antioxidants protect against glutamate-induced cytotoxicity in a neuronal cell line. J Pharmacol Exp Ther. 1989;250:1132-1140.

36. Bradbury MW, Deane R. Permeability of the blood-brain barrier to lead. Neurotoxicology. 1993;14:131-136.

37. Schurr A, West CA, Heine MF, Rigor BM. The neurotoxicity of sulfur-containing amino acids in energy-deprived rat hippocampal slices. Brain Res. 1993;601:317-320.

38. Olney JW. Role of excitotoxins in developmental neuropathology. APMIS Suppl. 1993;40:103-112.

39. Slivka A, Cohen G. Brain ischemia markedly elevates levels of the neurotoxic amino acid, cysteine. Brain Res. 1993;608:33-37.

40. Li X, Wallin C, Weber SG, Sandberg M. Net efflux of cysteine, glutathione and related metabolites from rat hippocampal slices during oxygen/glucose deprivation: dependence on gamma-glutamyl transpeptidase. Brain Res. 1999;815:81-88.

41. Choi DW, Rothman SM. The role of glutamate neurotoxicity in hypoxic-ischemic neuronal death. Annu Rev Neurosci. 1990;13: 171-182.

42. Olney JW, Zorumski C, Price MT, Labruyere J. L-cysteine, a bicarbonate-sensitive endogenous excitotoxin. Science. 1990;248:596-599.

43. Plaitakis A, Smith J, Mandeli J, Yahr MD. Pilot trial of branchedchain aminoacids in amyotrophic lateral sclerosis. Lancet. 1988;1: 1015-1018.

44. Ferkany J, Coyle JT. Heterogeneity of sodium-dependent excitatory amino acid uptake mechanisms in rat brain. J Neurosci Res. 1986;16:491-503

45. Olney JW, Ho OL, Rhee V, Schainker B. Cysteine-induced brain damage in infant and fetal rodents. Brain Res. 1972;45:309-313.

46. Gazit V, Ben-Abraham R, Coleman R, Weizman A, Katz Y. Cysteineinduced hypoglycemic brain damage: an alternative mechanism to excitotoxicity. Amino Acids. 2004;26:163-168.

47. Dilger RN, Baker DH. Excess dietary L-cysteine causes lethal metabolic acidosis in chicks. J Nutr. 2008;138:1628-1633.

48. Montine TJ, Picklo MJ, Amarnath V, Whetsell WO Jr, Graham DG. Neurotoxicity of endogenous cysteinylcatechols. Exp Neurol. 1997; 148:26-33.

49. Janaky R, Varga V, Hermann A, Saransaari P, Oja SS. Mechanisms of L-cysteine neurotoxicity. Neurochem Res. 2000;25:1397-1405.

50. Laine L, Shulman RJ, Pitre D, Lifschitz CH, Adams J. Cysteine usage increases the need for acetate in neonates who receive total parenteral nutrition. Am J Clin Nutr. 1991;54:565-567.

51. Savarese JJ, Belmont MR, savard PR, Sunaga H, Van Ornum S. The dose-response for immediate reversal of AV 002 by cysteine in the Rhesus monkey [abstract]. Anesthesiology. 2008;109:A1403.

52. Sunaga H, Malhotora JK, Savarese JJ, Heerdt PM. Cardiovascular effects of cysteine used for reversal of novel neuromuscular blocking drugs in dogs [abstract]. Anesthesiology. 2008;109:A367.

53. Sunaga H, Malhotora JK, Savarese JJ, Heerdt PM. Dose-response relationship for cysteine reversal of the novel muscle relaxant AV002 in dogs [abstract]. Anesthesiology. 2008;109:A364.

54. Tarver GJ, Grove SJ, Buchanan K, et al. 2-O-substituted cyclodextrins as reversal agents for the neuromuscular blocker rocuronium bromide. Bioorg Med Chem. 2002;10:1819-1827.

55. Cameron KS, Clark JK, Cooper A, et al. Modified gamma-cyclodextrins and their rocuronium complexes. Org Lett. 2002;4:3403-2406.

56. Bom A, Bradley M, Cameron K, et al. A novel concept of reversing neuromuscular block: chemical encapsulation of rocuronium bromide by a cyclodextrin-based synthetic host. Angew Chem Int Ed Engl. 2002;41:266-270. 
57. Cammu G, De Kam PJ, Demeyer I, Decoopman M, Peeters PA, Smeets JM, Foubert L. Safety and tolerability of single intravenous doses of sugammadex administered simultaneously with rocuronium or vecuronium in healthy volunteers. Br J Anaesth. 2008;100:373-379.

58. de Boer HD, van Egmond J, van de Pol F, Bom A, Booij LH. Sugammadex, a new reversal agent for neuromuscular block induced by rocuronium in the anaesthetized Rhesus monkey. Br J Anaesth. 2006;96:473-479.

59. Shields M, Giovannelli M, Mirakhur RK, Moppett I, Adams J, Hermens Y. Org 25969 (sugammadex), a selective relaxant binding agent for antagonism of prolonged rocuronium-induced neuromuscular block. $\mathrm{Br} J$ Anaesth. 2006;96:36-43.

60. Sorgenfrei IF, Norrild K, Larsen PB, Stensballe J, Ostergaard D, Prins ME, Viby-Mogensen J. Reversal of rocuronium-induced neuromuscular block by the selective relaxant binding agent sugammadex: a dosefinding and safety study. Anesthesiology. 2006;104:667-674.

61. Naguib M. Sugammadex: another milestone in clinical neuromuscular pharmacology. Anesth Analg. 2007;104:575-581.

62. Epemolu O, Bom A, Hope F, Mason R. Reversal of neuromuscular blockade and simultaneous increase in plasma rocuronium concentration after the intravenous infusion of the novel reversal agent Org 25969. Anesthesiology. 2003;99:632-637.

63. Organon USA. FDA Anesthetic and Life Support Advisory Committee Meeting. Sugammadex Sodium Injection (NDA 22-225). March 11 2008. Briefing Document. Last Accessed March 8, 2009. Available from: http://www.fda.gov/ohrms/dockets/ac/08/briefing/20084346b1-02-Organon.pdf.

64. Naguib M. Sugammadex may replace best clinical practice: A misconception. Anesth Analg. 2007;105:1506-1507.

65. Gijsenbergh F, Ramael S, Houwing N, van Iersel T. First human exposure of Org 25969, a novel agent to reverse the action of rocuronium bromide. Anesthesiology. 2005;103:695-703.

66. de Boer HD, van Egmond J, van de Pol F, Bom A, Booij LH. Chemical encapsulation of rocuronium by synthetic cyclodextrin derivatives: reversal of neuromuscular block in anaesthetized Rhesus monkeys. Br J Anaesth. 2006;96:201-206.
67. de Boer HD, van Egmond J, van de Pol F, Bom A, Booij LH Reversal of profound rocuronium neuromuscular blockade by sugammadex in anesthetized Rhesus monkeys. Anesthesiology. 2006;104:718-723.

68. Eleveld DJ, Kuizenga K, Proost JH, Wierda JM. A temporary decrease in twitch response during reversal of rocuronium-induced muscle relaxation with a small dose of sugammadex. Anesth Analg. 2007; 104:582-584.

69. Zhang MQ. Drug-specific cyclodextrins: the future of rapid neuromuscular block reversal? Drugs Future. 2003;28:347-354.

70. Gillespie JI, Harvey IJ, Drake MJ. Agonist- and nerve-induced phasic activity in the isolated whole bladder of the guinea pig: evidence for two types of bladder activity. Exp Physiol. 2003;88:343-357.

71. Proost JH, Eriksson LI, Mirakhur RK, Roest G, Wierda JM. Urinary, biliary and faecal excretion of rocuronium in humans. Br J Anaesth. 2000;85:717-723.

72. Sparr HJ, Vermeyen KM, Beaufort AM, et al. Early reversal of profound rocuronium-induced neuromuscular blockade by sugammadex in a randomized multicenter study: efficacy, safety, and pharmacokinetics. Anesthesiology. 2007;106:935-943.

73. Staals LM, Snoeck MM, Hunter JM, Heeringa M, Driessen JJ. Pharmacokinetics of rocuronium and sugammadex in patients with normal and impaired renal function. Cape Town, South Africa. 13th World Congress of Anesthetists (WCA), March 2-7, 2008.

74. Amao R, Zornow MH, Cowan RM, Cheng DCH, Allard M. Sugammadex safely reverses rocuronium-induced blockade in patients with pulmonary disease [abstract]. Anesthesiology. 2007;107: A1582.

75. Naguib M, Brull SJ. Sugammadex: a novel selective relaxant binding agent. Expert Rev Clin Pharmacol. 2009;2:37-53.

76. Dahl V, Pendeville PE, Hollman MW, Heier T, Blobner M. Reversal of rocuronium-induced neuromuscular blockade by sugammadex in cardiac patients [abstract]. Anesthesiology. 2007;107:A1581.
Drug Design, Development and Therapy

\section{Publish your work in this journal}

Drug Design, Development and Therapy is an international, peerreviewed open-access journal that spans the spectrum of drug design and development through to clinical applications. Clinical outcomes, patient safety, and programs for the development and effective, safe, and sustained use of medicines are a feature of the journal,

\section{Dovepress}

which has also been accepted for indexing on PubMed Central. The manuscript management system is completely online and includes a very quick and fair peer-review system, which is all easy to use. Visit http://www.dovepress.com/testimonials.php to read real quotes from published authors. 